\title{
ACTIVE CONTROL OF COMBUSTORS AFTER TWENTY YEARS' EFFORTS
}

\author{
F. E. C. Culick and S. Palm
}

\begin{abstract}
Active control of combustion was proposed by Bollay [1]. Following that idea, Tsien [2] worked out an analysis of controlling low-frequency oscillations in a liquid rocket but no successful experimental results followed. More than thirty years passed before the first laboratory demonstrations were performed at Cambridge University. Interest grew rapidly in the 1990s due to potentially wonderful applications to practical combustion systems including liquid and solid rockets, gas turbines, and thrust augmentors. Dreams have not materialized: There are presently no operational control systems, despite considerable efforts, and examples of partially controlled phenomena. Only one practical installation for control of oscillations has been documented, for a large Siemens machine [3]. Its use has been rendered unnecessary by further experimental work leading to development of successful passive control with modifications of hardware [4]. The purpose of this paper is to examine briefly some of the reasons that active control of combustion has failed to become the panacea widely anticipated two decades ago. The authors' view is that the subject is far from exhausted, but rather requires carefully planned research to understand the basis of successful applications.
\end{abstract}

\section{INTRODUCTION}

Bollay's original proposal that combustion systems could be actively controlled grew out of his interests and work on feedback control of systems common to aeronautical applications. His suggestion was grounded in classical control theory. Although Bollay did not discuss this interpretation, his idea is captured with the block diagram shown in Fig. 1 [5] which shows a system controlled with passive devices $C_{G}$ and $C_{Q}$ as well as feedback $C_{f}$ and $C_{f b}$. The dynamics of the system are represented by $G$, and the dynamics of the combustion processes by $Q$.

By applying elementary rules for manipulating block diagrams, one can simplify the diagram of Fig. 1 to that shown in Fig. 2 representing the same dynamical behavior $F \rightarrow P$. All of the examples of linear systems discussed in 


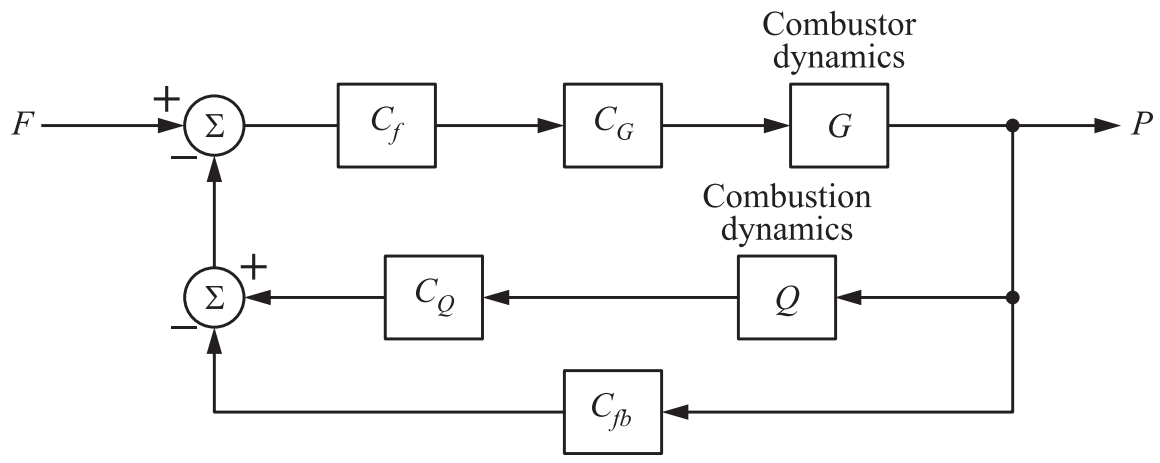

Figure 1 Block diagram for a system containing passive $\left(C_{G}\right.$ and $\left.C_{Q}\right)$ and feedback $\left(C_{f}\right.$ and $\left.C_{f b}\right)$ control

this paper may be cast in this form if the ideas of classical feedback control are followed.

What distinguishes control of combustion systems (the term 'combustor' is usually equivalent to 'combustion system' in the present context) are mainly the five attributes listed below:

(1) Internal instabilities;

(2) Substantial time lags;

(3) Intrinsic nonlinearities;

(4) High levels of noise; and

(5) The action of control changes properties of the system.

Not all of these attributes may be equally influential on the behavior of a given system, but the possibilities must be recognized.

The primary motivation for considering feedback control was the common occurrence of instabilities in all types of system. This is a physical phenomenon 'explained' with the block diagrams of Figs. 1 and 2: Adding feedback (e.g., a resonating enclosure) to an amplifier (the combustion system) can produce an oscillator. It is nicely analogous, for example, to the situation when a laser oscillator is made by setting an amplifying medium (e.g., an appropriately prepared gas) inside an optical resonator formed by two mirrors.

However, the really difficult task is determining the basic cause of the instability, the mechanism encapsulated by the first attribute (1). Maybe, then one can do something about it so the system is stable under a broader range of conditions. Unlike the common situation for traditional applications of feedback 
control, the systems to be controlled are almost always intrinsically unstable, the reason for applying control. Often unstable behavior involves explicitly one or more time lags, or can be formally described in terms of time lags. A difficulty is soon encountered, that theories of feedback are lim-

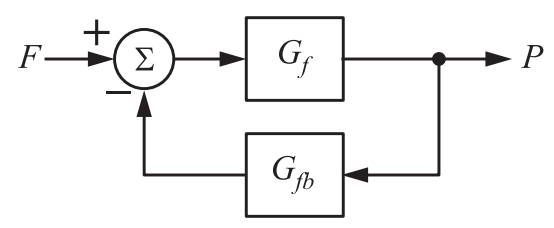

Figure 2 General block diagram of a combustion system with passive and active control ited in respect to the ranges of disturbances that can be accommodated. Theories are quite limited when time lags are present, particularly, if the open loop system is unstable and contains more than one time lag.

Combustion systems are usually unstable in the absence of external forces; their motions therefore are limited by internal nonlinear effects. Many consequences of nonlinear processes commonly appear in observed behavior. Nonlinear feedback control is an undeveloped difficult subject that has hardly been considered for combustion systems. As a practical matter, linear feedback control can, of course, be used without regard for a system's actual characteristic — but possible results cannot be anticipated.

It is probably true that the influences of noise can often be ignored without adverse consequences. However, certain details of observed behavior may require accounting for noise. A brief description based on one point of view has been given by Culick [5].

Probably the least understood factor, and perhaps the most significant obstacle to successful control of combustion systems, is summarized by the attribute (5). It is a possibility that has been largely overlooked in practically all the research reported to date, although examples have appeared in some descriptions of experimental work. The ease with which the characteristics of combustion systems may change under both quasi-steady and truly dynamical conditions is an enormous difference compared with the situations for which classical and modern feedback control were developed. The picture reproduced as the third part of Fig. 7 below is one of the earliest evidences.

\section{SOME EARLY RESULTS}

Tsien's example [2] is probably the simplest case illustrating several basic features of the problem. His idea was to control low-frequency oscillations called 'chugging,' by varying a capacitance installed in the system (Fig. 3).

The equation for the chamber pressure, taken to be uniform throughout the volume, is 


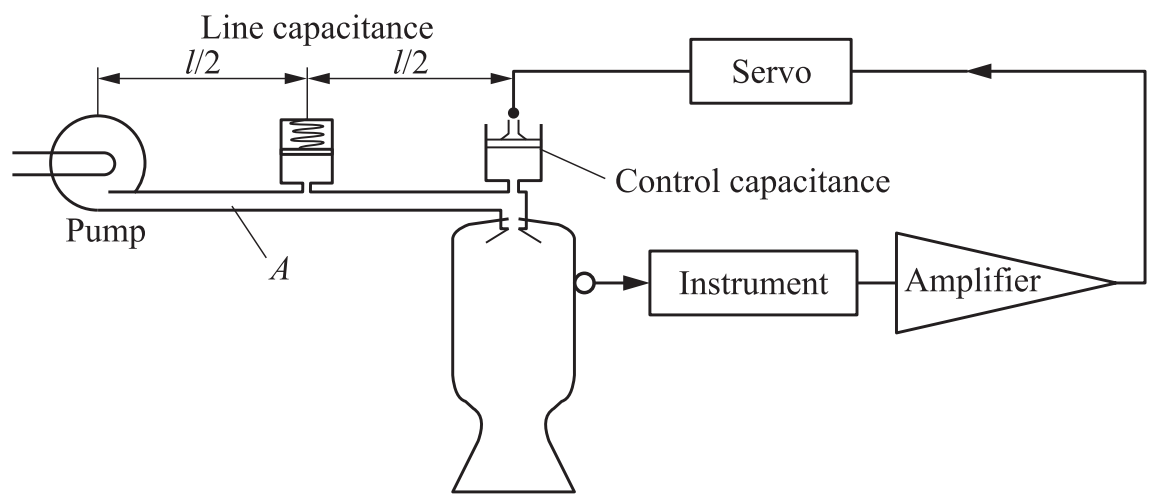

Figure 3 Schematic of the first proposal for active feedback control of the dynamics in a combustion system [2]

$$
\frac{d^{2} p^{\prime}}{d t^{\prime}}+2 \alpha \frac{d p^{\prime}}{d t}+\omega_{0}^{2} p^{\prime}=\beta p^{\prime}(t-\tau)+u(t)
$$

where $u(t)$ is an externally applied signal and $\beta p^{\prime}(t-\tau)$ is the 'feedback control signal' (here, proportional to the delayed pressure $p^{\prime}(t-\tau)$ ). For oscillations having frequency $\omega$, the Laplace transform of Eq. (1) gives

$$
P(s)=\frac{\beta e^{-s t} G(s)}{1-\beta e^{-s t} G(s)} U(s)
$$

and

$$
G(s)=\frac{1}{s^{2}+2 \alpha s+\omega_{0}^{2}}
$$

is the transfer function for the system, which here is the pressure field in the chamber. The formula (2) is the response or 'output' of the system $G(s)$ with the feedback $\beta e^{-s t}$. These results can be represented with the feedback loop shown in Fig. 4.

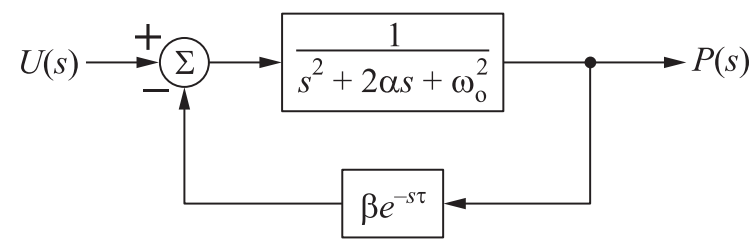

Figure 4 Block diagram for the system shown in experiment 


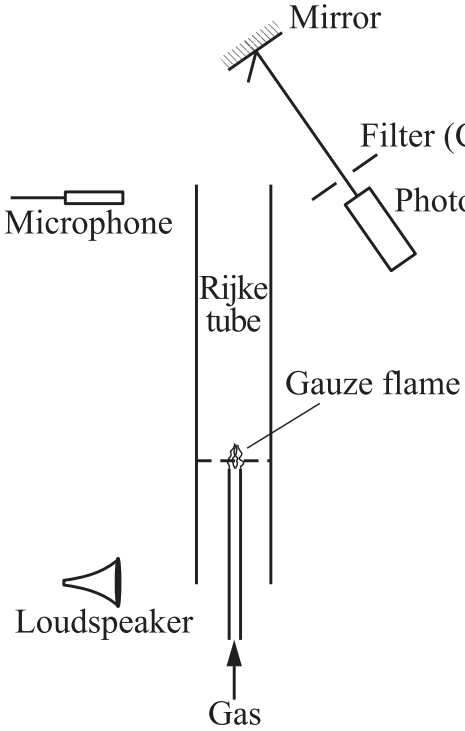

(a)

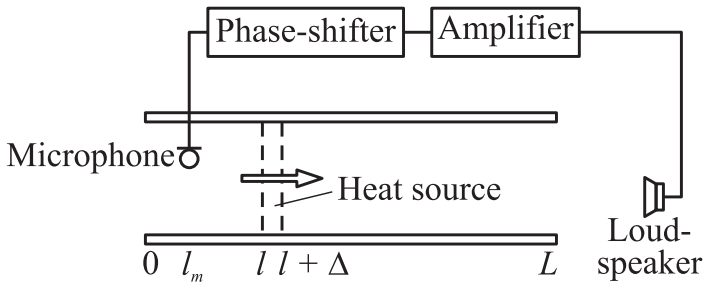

(b)

Figure 5 Feedback control of a Rijke tube by injection of acoustic waves: $(a)$ emitted radiation as the sensed variable $[6]$ and $(b)$ pressure as the sensed variable with air forced by a blower through the horizontal tube $[7,8]$

Using a combination of the Nyquist criterion and Satche's method for handling the exponential in Eq. (2), Tsien showed that the system could be stabilized for any value of the time lag $\tau$. His conclusion prompted the first experiments at the Aerojet Company, apparently either unsuccessful or inconclusive due to inadequate hardware and instrumentation.

Thirty years later in his Masters thesis, Dines [6] added simple instrumentation to a Rijke tube and carried out the first laboratory tests of active control of a combustion system. His apparatus is sketched in Fig. 5. In her Ph.D. research and subsequently, Heckl [7, 8] built on Dines' work and executed the earliest extended series of tests, using the apparatus sketched in Fig. $5 b$.

The works by Dines and Heckl were the primary experimental bases for the U.S. Patent [9]. That document is a good description of their ideas for applying the method to both the primary combustor and the thrust augmentor of a gas turbine. It is probably the first discussion of the main elements of an active control system for a controller as conceived by the Cambridge group. At that time, the difficulties in making such a control system actually work with an actual combustor were yet to be discovered. The proposal covered in the patent is foresighted in two respects not actually accomplished for about $8-9$ years: The 


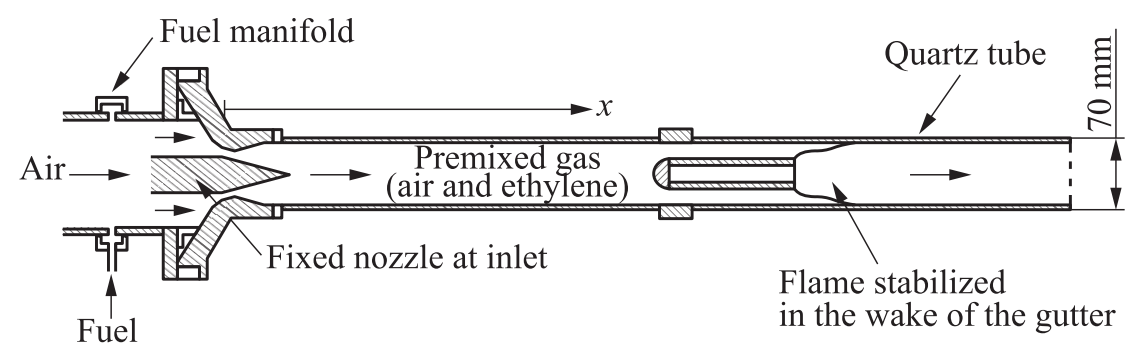

(a)

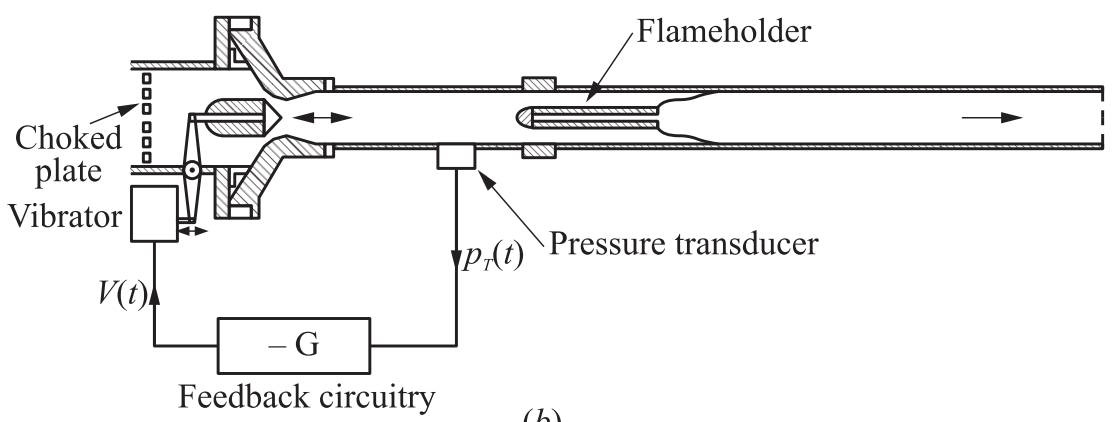

(b)

Figure 6 Cambridge apparatus: (a) fixed nozzle for studies of longitudinal instabilities [10] and $(b)$ variable nozzle for experiments to determine transfer functions and for active control $[11]$

authors proposed that control be exerted by modulation of the fuel supply; and that a multiinput, multioutput (MIMO) system would be required.

Immediate subsequent research at Cambridge produced interesting results obtained from the apparatus sketched in Fig. 6. The work was performed under the supervision of Prof. Dowling with financial support by Rolls Royce as part of their effort to reduce the consequences of oscillations in thrust augmentors. In their program, the Cambridge group were first to investigate actuation by modulating the fuel supply, proposed in the patent [9]. This clearly is a more practical method than one based on loudspeakers, as shown in Fig. 5, and is now universally used except for simple demonstrations.

Some time later, a modest demonstration of control of an instability in an augmentor was reported in [12]. The apparatus was clearly special, and the work did not generate further experimentation following the same approach.

At about the same time, an interesting research program was initiated in the combustion laboratory at École Centrale, Paris, in collaboration with a group at the Technische Universität München. The greater part of the collaborative programs was reported by Lang et al. [13], and by Poinsot et al. [14, 15]. Figure 7 


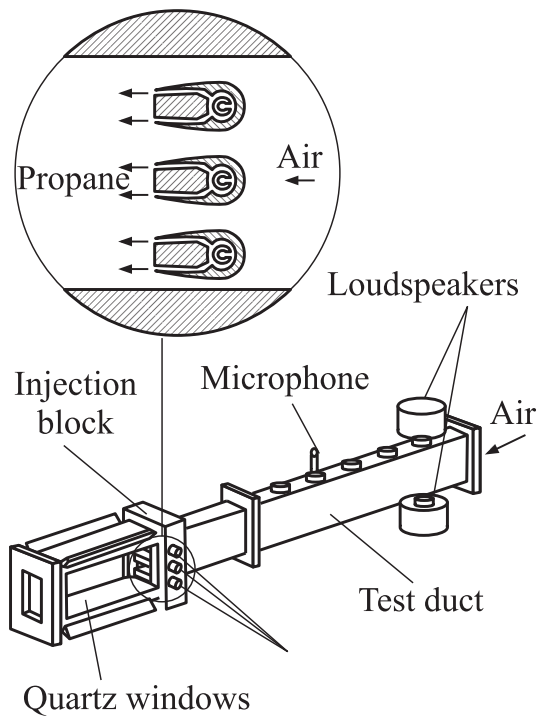

(a)

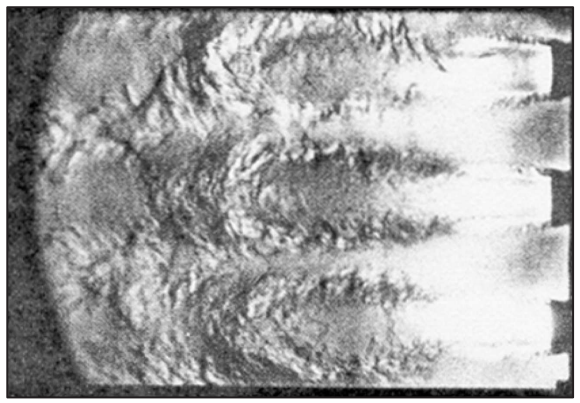

(i)

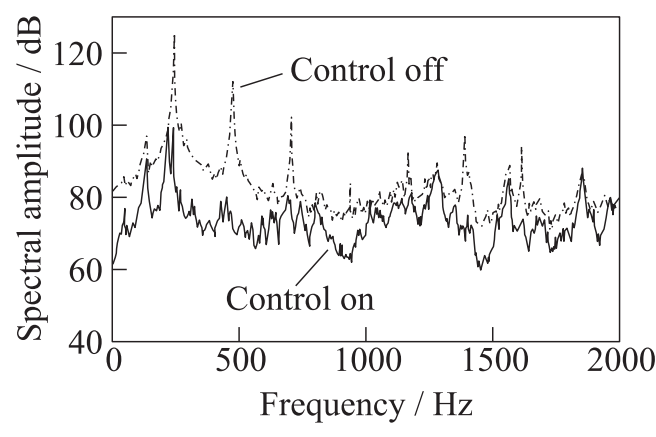

(b)

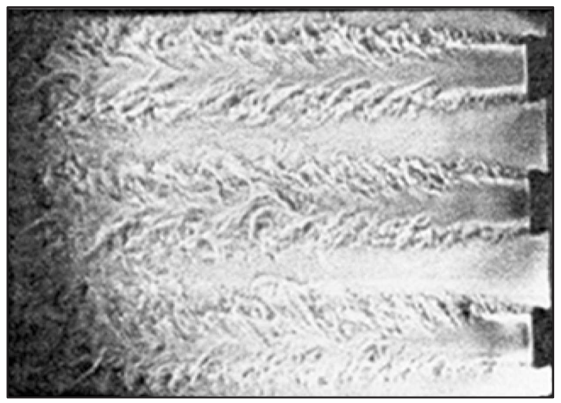

(ii)

(c)

Figure 7 Feedback control at École Centrale (a) apparatus with a 250-kilowatt combustor; $(b)$ effects of control on the sound emission; and (c) Schlieren photographs of the combustion region $(i)$ without and $(i i)$ with control $[14,15]$

shows their apparatus and, for the purposes here, their most significant results. Figure $7 b$ shows the significant effect of control, here executed by the action of loudspeakers, on the spectral amplitude function of the oscillations. That result is fairly typical of the findings reported by a number of groups in the late 1980s and 1990s. Note that the most intense component of the spectrum has been reduced by about $20-25 \mathrm{~dB}$. 
Most noteworthy is Fig. $7 c$. The photograph is perhaps the first evidence that control of oscillations may have substantial effect on both the average and unsteady distributions of combustion. It is by no means clear what the effects were, but there are undeniable differences in the schlieren photographs of the combustion zones in the uncontrolled (Fig. $7 c, i$ ) and controlled states (Fig. $7 c, i i$ ). Other pictures of similar phenomena observed in different experiments have been published; this early result already seems to make the point well.

\section{OPERATIONAL ACTIVE CONTROL SYSTEM}

With the exception of the theoretical discussions in the patent [9] and analyses by Fung et al. [16, 17], virtually all results obtained for control of combustion were worked out for gaseous systems until the mid-1990s*. Several doctoral programs at the Technische Universität München had significant consequences for applications to control of liquid-fueled systems.

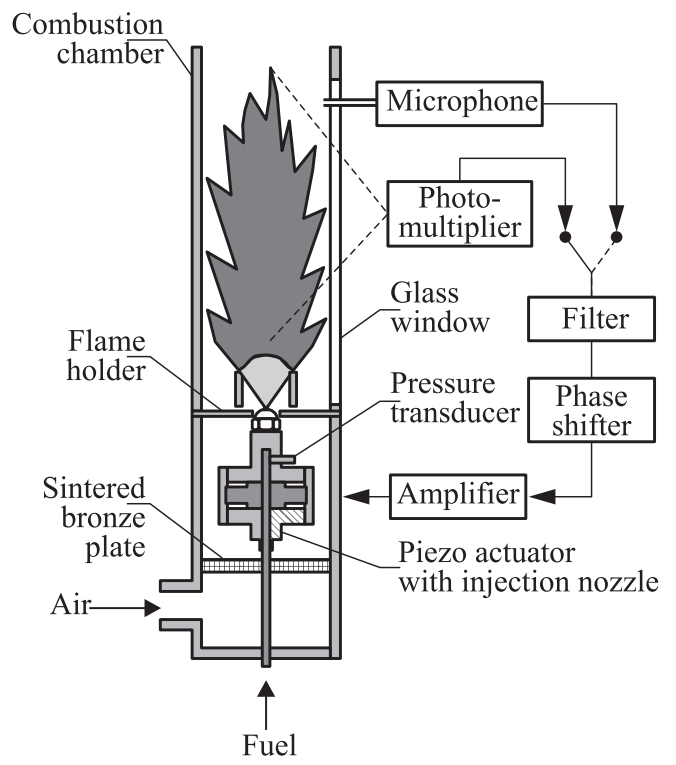

(a)

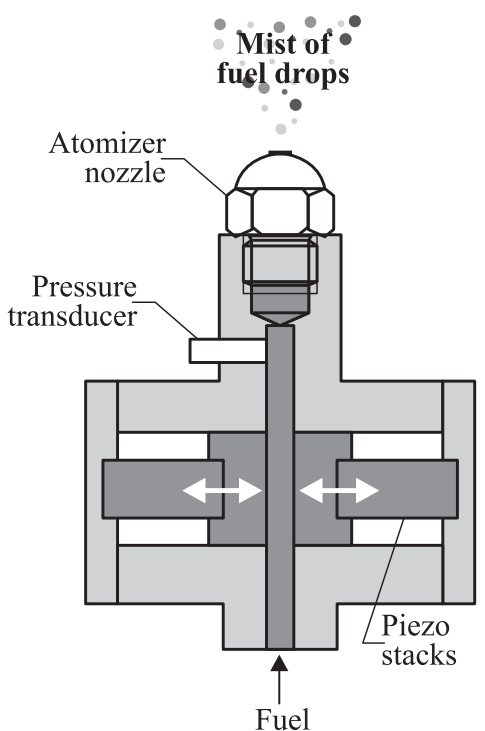

(b)

Figure 8 Feedback control at Technische Universität München: (a) apparatus and (b) the piezo actuator [20]

* Small effects of a modulated supply of liquid fuel had been noted in a patent application by Gulati and Bigelow [18]. 


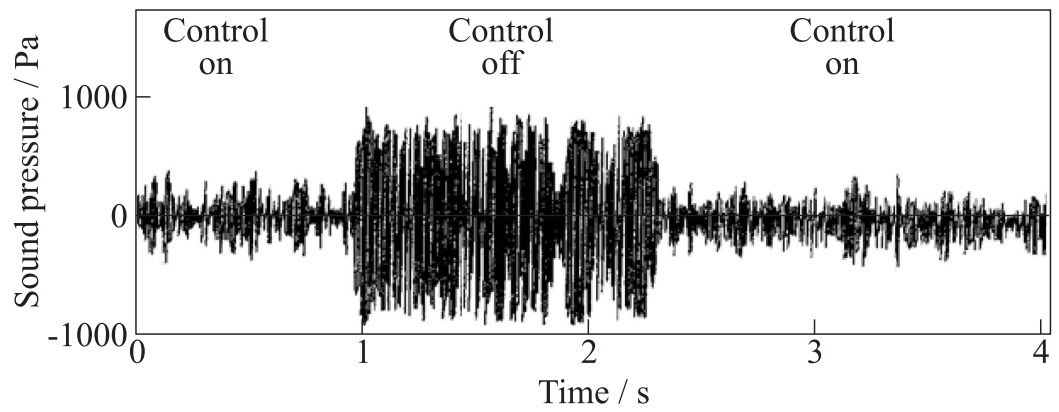

(a)

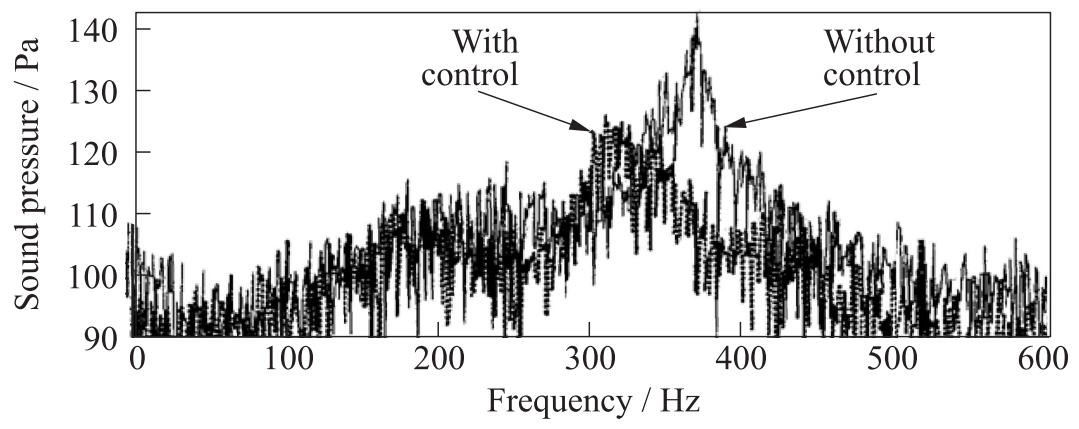

(b)

Figure 9 Test results obtained with the apparatus shown in Fig. 8 and Fig. 14 of [20]

The work was preceded by earlier research not covered here, but the results most directly influential in the subjects discussed in this way were reported in the papers $[19,20]$. Probably their most important contribution is the use of a piezo-electric actuator to modulate all or a portion of the fuel. Sketches of their laboratory apparatus and actuator are given in Fig. 8; an example of attenuation of oscillations is reproduced in Fig. 9.

A really interesting - and instructive! - consequence of the research in München was that the work led directly, and surprisingly quickly, to development of a system adopted for use in large operational Siemens gas turbines. Moreover, they were, and apparently remain, the only MIMO control systems developed for combustors. The hardware, and experience in practice, are welldescribed in [21]; details of the control system were reported by Hermann et al. $[3,21]$. Control systems were eventually installed on fourteen V94.3A gas turbines, each used in a 270-megawatt electric power generation unit. Two of the machines accumulated a total greater than 140,000 hours of operation with no failure. 


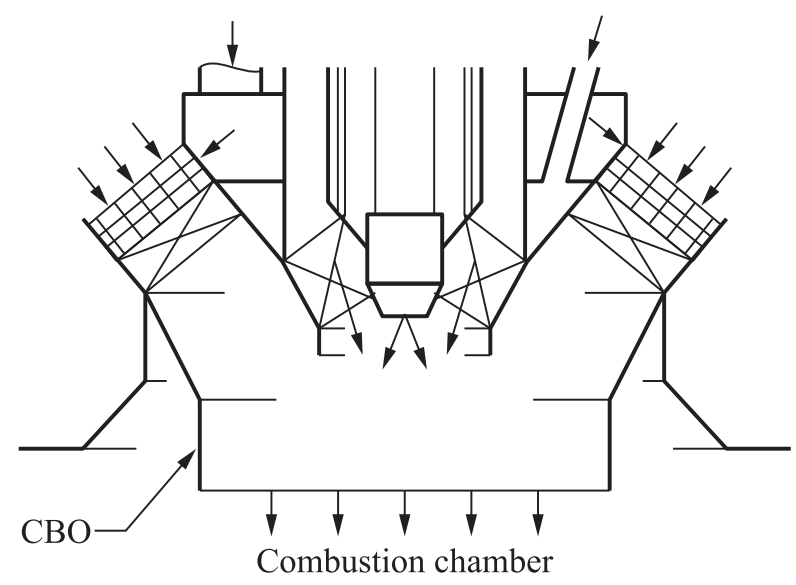

Figure 10 Addition of the cylindrical burner outlet (CBO) to the Siemens Hybrid Burner [4]

The story ends dramatically, if not happily for those desiring practical usage of feedback control. Continuing efforts by engineers at Siemens at last located the mechanism for the instability. Apparently, interactions at the inlet for the fuel supply initiated and sustained acoustic waves, whose principal motions were (roughly) in directions not including that of the average axial flow. Addition of a fitting to the burner outlets (Fig. 10) was the main effective modification. Misalignment of a few burner supply nozzles also aided suppression of the instability by destroying azimuthal symmetry. The net result was that the active control system was reportedly eliminated from operational use.

\section{RESEARCH ON ACTIVE CONTROL OF COMBUSTION, 1990-PRESENT}

As national and international regulations governing emissions became increasingly stringent for both transportation and stationary powerplants, attention was directed to combustion at lower temperatures. The reason is shown in Fig. 11. It is a basic result that formation of nitrogen oxides is favored by high temperatures, established by Zel'dovich [23] and confirmed beyond doubt by many experimental measurements.

That simple fact motivated and has dominated research in combustion dynamics for two decades. The drive towards lean combustion has forced design of combustors which, operating near the lean limit, are ever closer to their stability limits. Sources of the instabilities are intrinsic to any system and simply can- 


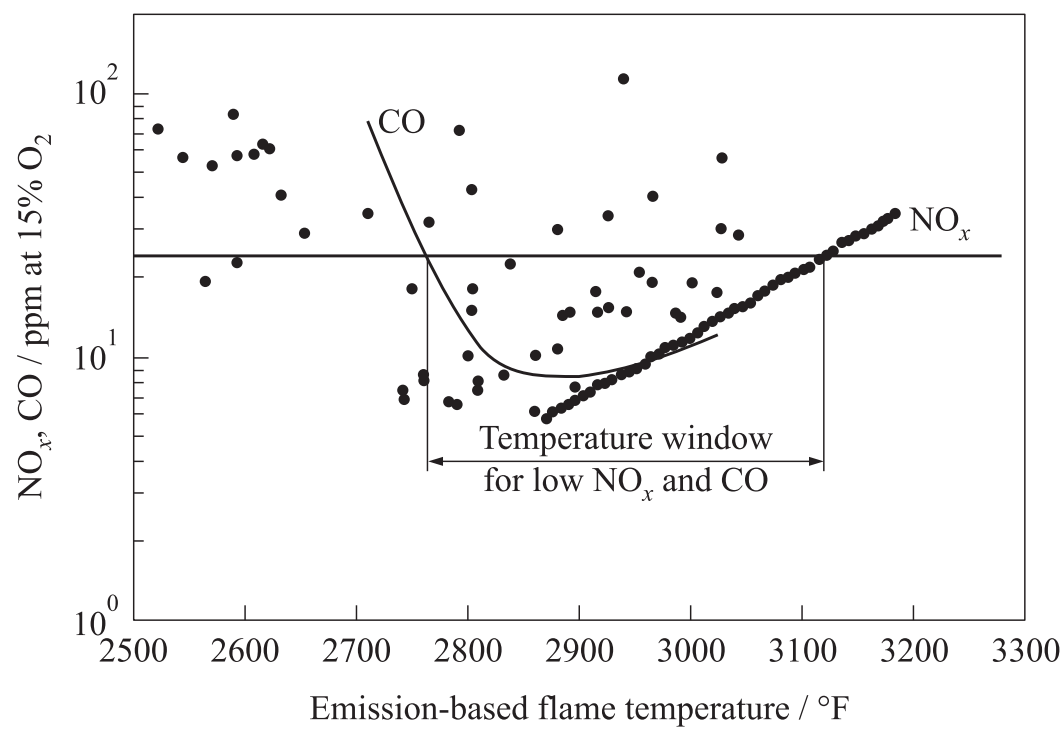

Figure 11 Concentrations at equilibrium of carbon monoxide and oxides of nitrogen $[22]$

not be designed away in any obvious fashion. For example, fluctuations of flow velocity and mixture ratio associated with flow past edges (as during injection), or separation and recirculation at steps or 'corners,' become naturally amplified under lean conditions. Boundary layers, inevitably turbulent, may develop and shed vortices which interact with the main flow and grow by extraction of energy.

Discovering what processes are active in a given design, and their relative importance as operating conditions change, presents horribly complicated experimental problems in actual combustors. Applications of computational fluid dynamics (CFD) have grown considerably in the recent past - see, for example, several articles in the volume edited by Lieuwen and Yang [24]. Capabilities for studying stability of combusting flows in actual configurations remain beyond reach at present.

Thus, it is not surprising that almost all of the work in this field has been experimental, or perhaps better put, demonstrational. Following the works discussed in Section 2, activity in the area increased greatly in both the U.S. and Europe. The report of a workshop sponsored by AGARD [22] gives a good summary of the state of the field in 1996. Mainly topics of interest to the aerospace community were covered. The recent collection of papers compiled by Lieuwen and Yang [24] is the most thorough survey of problems arising in combustion systems for gas turbines. 
Lesser efforts have continued mainly in three other directions which may be identified roughly as belonging to three separate classes:

(i) afterburner (thrust augmentor) instabilities;

(ii) high frequency motions or instabilities in solid rockets; and

(iii) control of lean blowout (LBO) in gas turbines. Little interest has been shown in actively controlling instabilities in liquid rockets.

Research activities directed to use of feedback control may be divided qualitatively into three types:

(i) those which emphasize the control aspects;

(ii) those dominated by the physical character of the dynamical motions being studied; and

(iii) those which consciously attempt to merge the first two.

It is impossible to separate the control problems entirely from the physical behavior of the system under consideration, but much of the work carried out in the past 10-15 years has tended to emphasize methods of control which had been developed previously for systems not involving flow or combustion. Applications of those methods, perhaps in modified form, have tended to proceed without special attention to attributes of the systems being studied.

The largest and most successful research activity in this area in the U.S. has been carried out at Georgia Tech beginning in the mid-1990s (see, e.g., [25, 26]). Two dominant themes have guided the work which is in a sense a natural extension and elaboration of the Cambridge approach but applied to liquidfueled gas turbines: development of a fast 'observer,' i.e., digital identification of detailed properties, such as the spectral components of an instability; and use of a new form of magnetostrictive actuator used to modulate a secondary supply of fuel. The program is summarized well in the recent useful review by Prof. Zinn [26]. A patent issued to Neumeier and Zinn [27] contains descriptions of much of the technical content of the Georgia Tech work. Figure 12 is a schematic summary of the main achievements.

The doctoral dissertation by Johnson [28] is a useful introduction to the Georgia Tech work, particularly the more recent efforts in adaptive control. Practical difficulties in the applications of automated control long ago led to the idea of building into a system some means of compensating - without external intervention - for changes in the environment or in the system itself. That is broadly the character of adaptive control. Presented with the difficulties and basic uncertainties in the physical characteristics of the systems, those working in this field very early explored the possibilities presented by adaptive control. Åstrom and Wittenmark [29] have given a comprehensive and 


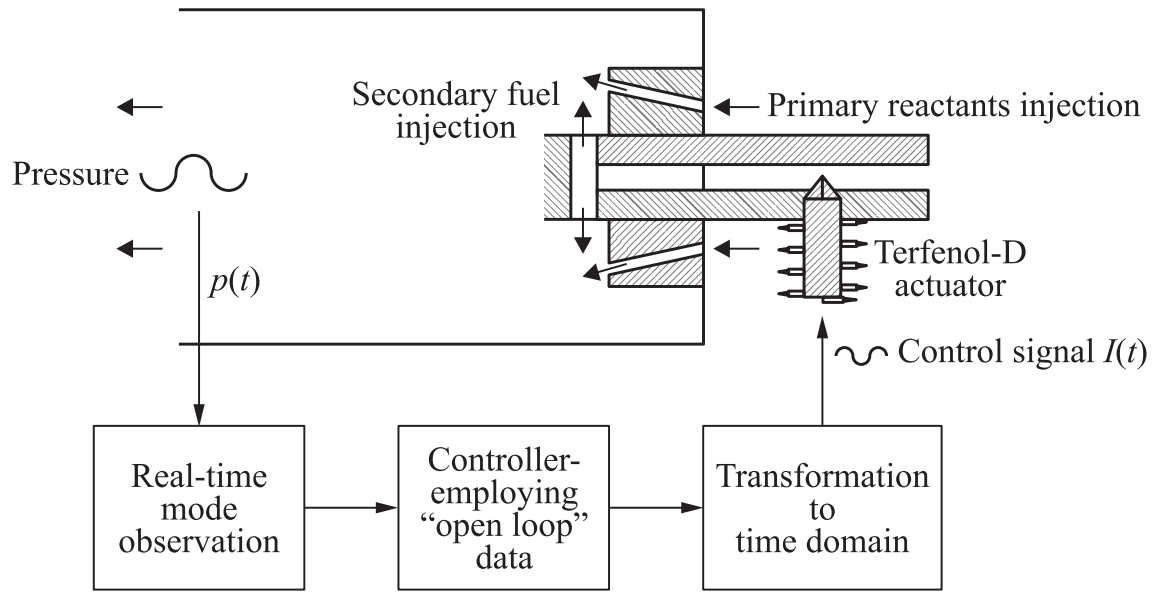

Figure 12 Schematic of Georgia Tech method of active control [26]

useful text covering the field. They do not discuss fluid or combustion systems.

Billoud et al. [30] first studied the use of adaptive control in the present context. The subject was pursued in greater depth by Evesque et al. [31-33]. The publications on the subject have mainly covered applications based on established procedures using methods worked out for applications in electrical engineering. Quite simple treatments of the combustion and flow fields have served for illustrative purposes.

There is a large number of papers dealing with various observations and experiments directed to special aspects of the general field, control of combustion dynamics. Some, such as Lieuwen et al. [34], are intended to establish details of mechanisms, but usually not under conditions closely approximating those in operational combustors. In particular, the geometries are almost always simplified in the interests of isolating particular features. Experience, for example, with instabilities in solid rockets suggests that may not always be a wise tactic (see [5] for an extended coverage of experiences in that area).

As the last example, a short discussion of some aspects of instabilities and their control in full-scale combustors is given for two contrasting types of operational designs. It has not been possible yet to obtain copies of all early relevant references, so parts of the story are based on word-of-mouth information. In broad outline, the story is certainly true.

In the 1970s, NASA sponsored the Experimental Clean Combustor Program (ECCP) "directed toward the development and experimental engine evaluation of the technology required to reduce pollutant emissions for both current and 
future gas turbine engine combustors" [35]. There were two participants in the three-phase program: General Electric (GE) modified the combustor for their engine CF6-50 which was used, for example, in Boeing 747 aircraft; and Pratt and Whitney $(\mathrm{P} \& \mathrm{~W})$, after preliminary work in the first two phases of the program, used their new experimental design called the Vorbix combustor fitted to a JT9D-7A engine in Phase III.

The final reports of Phase III [35, 36] document the results of the programs. What matters here are the broad conclusions drawn with the help of thirty years' progress since the ECCP: The GE research in ECCP was the beginning of lengthy developments leading to several forms of lean premixed (LP) or lean prevaporized, premixed (LPP) and lean direct injection (LDI) combustors in current use. Lean prevaporized, premixed combustors are generally in use as aeroengine derivatives for the industrial or land based gas turbines, whereas LP and LDI combustors are being developed for aeroengine applications.

In the discussions below, these combustors will be called 'lean.' P\&W research has led to the Technology for Advanced Low Nox (TALON) series of combustors, which are installed in all combustors which are recently certified or are under development at P\&W. As Sabnis [37] has described, the TALON combustors are based on the rich-quench-lean (RQL) idea for reducing emissions.

Examples of the two types of combustor design are shown in simplified forms in Fig. 13. Note that quarter-wave tubes as acoustic dampers are integral to the GE design of the LM 6000. Moreover, a kind of active control is used, a form of parametric control [38]. That is, there is no actuation at high frequencies, but stable operation is maintained by 'slow' changes of parameters governing the operating state of the chamber.

The principle on which the lean combustion designs are based was explained earlier. In a general sense, conditions are not far from equilibrium as the flow progresses through the chamber. Quite differently, nonequilibrium (the 'quench') is an essential step in flow through an RQL combustor.

But in return for being forced to deal with a fundamentally more complicated flow field, look at the simple mechanical design one gets! Already with the Vorbix, an example of early RQL combustors, certain goals were set for the program. The $\mathrm{P} \& \mathrm{~W}$ engine with the Vorbix combustor produced oxides of nitrogen $10 \%$ below the goal; carbon monoxide $25 \%$ below the goal; and total unburned hydrocarbons $75 \%$ below the goal. Great results, but the smoke emissions failed to meet the requirements.

There were several other deficiencies. The net result was that many people, including those making decisions at GE, evidently concluded that the Vorbix or RQL, or other sorts of 'nonequilibrium' combustors, did not offer a good basis for development. Oxides of nitrogen, carbon monoxide, and unburned hydrocarbons were reduced respectively by $30 \%, 55 \%$, and $95 \%$ for the modified CF6-50 engine, with "acceptable smoke levels." The combustor was an early lean design (a "dual annular combustor" or DAC) which has been highly developed since. The dry 


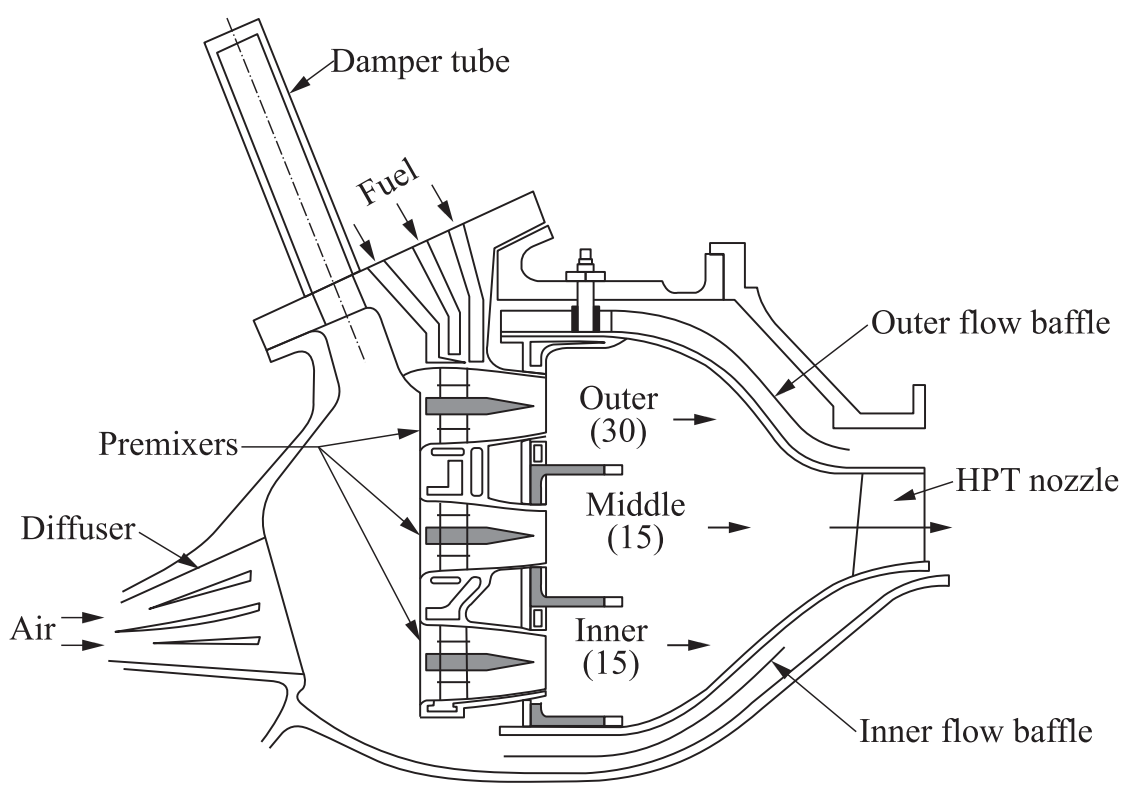

(a)

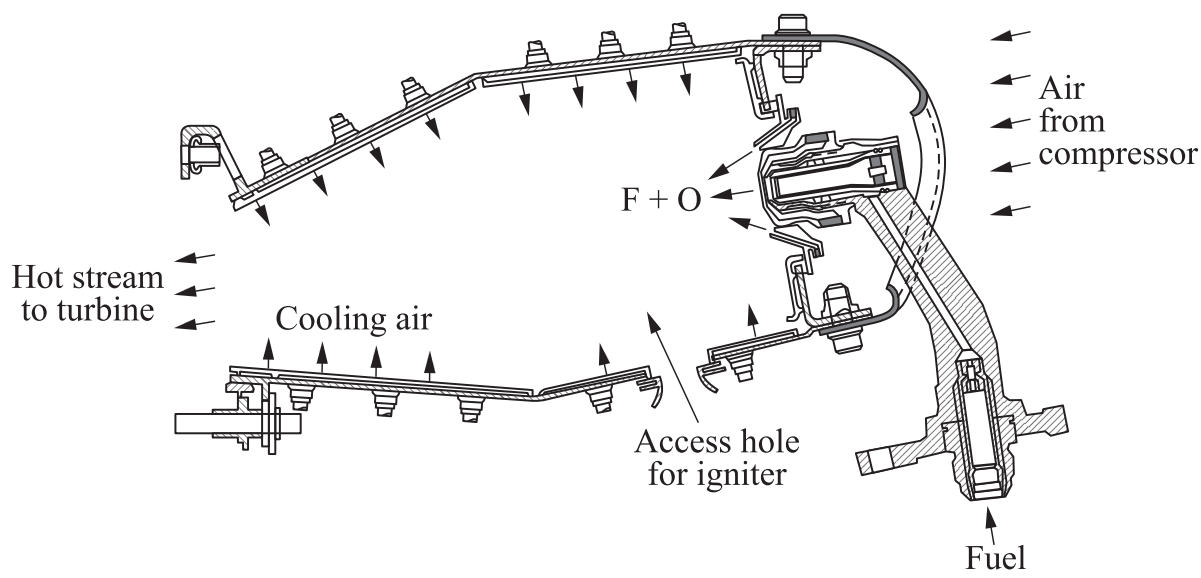

(b)

Figure 13 Two kinds of low-emission combustor design: (a) LP, the GE LP 6000 [38]; and $(b)$ RQL, the P\&W TALON II [39]. Sketches show sections of annular configurations. For a section of the LP GE CFM-56, see [40] 
low emissions combustor (Fig. 13a) is one form having three arrays of injectors, and Fig. $13 b$ shows the P\&W TALON II.

The great deficiency of lean combustors is of course the inevitable problem with combustion instabilities. Whether that is the reason $\mathrm{P} \& \mathrm{~W}$ chose the RQL route we do not know at this time, but it was a magnificent decision. Eventually, all emissions requirements were met, and as a significant secondary benefit, the relative simplicity of the TALON design is apparent from comparison of Fig. 13b, on the one hand, with Fig. $13 a$ and the LP design of the GE CFM-56 [40], on the other. Development of the TALON series continues, but just how far the emissions can be reduced is not yet understood. It must be emphasized also that under suitable conditions, TALON combustors will have instabilities, but that problem is substantially less severe than in lean combustors.

For all combustor designers, the prospect of combustion instabilities and further emissions requirements is a pressing problem, perhaps solved only by significant changes in combustor design. One promising possibility being actively pursued by GE and others is the trapped vortex combustor (TVC). A good description of the basic ideas and recent experimental results have been given by Haynes et al. [41]. Figure $14 a$ is a drawing of their best device; Fig. $14 b$ is a sketch suggestive of a practical installation.

A striking attribute of both the RQL and TVC designs is the relative absence of combustion instabilities. Any combustor has limits on the ranges of operation with steady conditions. Those limits are unfortunately on the edges of the working envelope for a machine designed to use lean combustion (LP and LPP combustors). That fact has determined formulation of industrial and national research programs in the US and elsewhere. With the growing attractiveness of RQL and TVC combustors, it is likely wise to reexamine the bases for the formulation of research programs, for example, in universities.

Perhaps the most immediate question is: Why is there such an obvious difference between the stability characteristics of lean combustors, on the one hand, and RQL combustors, on the other? It is true that a difference in behavior is not a surprise, but it is another matter to understand the basic reasons. One must note first that the distinctions between the two types of designs are really based on qualitative information - whether or not instabilities occur — not on quantitative measurements. So, one must be careful not to infer too much from limited experimental information. Consequently, the following remarks can be offered as tentative and certainly qualitative explanations.

Consider the case of lean combustion first. It is, of course, well-established that as the lean limit is approached, intermittent behavior will occur, perhaps, generating oscillations in a chamber. A reason long quoted is fluctuations in equivalence ratio. For example, that is a convenient input to initiate oscillations in numerical computations of unsteady flows in combustors. The physical processes acting may then be influential throughout the combustion chamber. Or, what often seems to be the case in experiments, detailed behavior in re- 


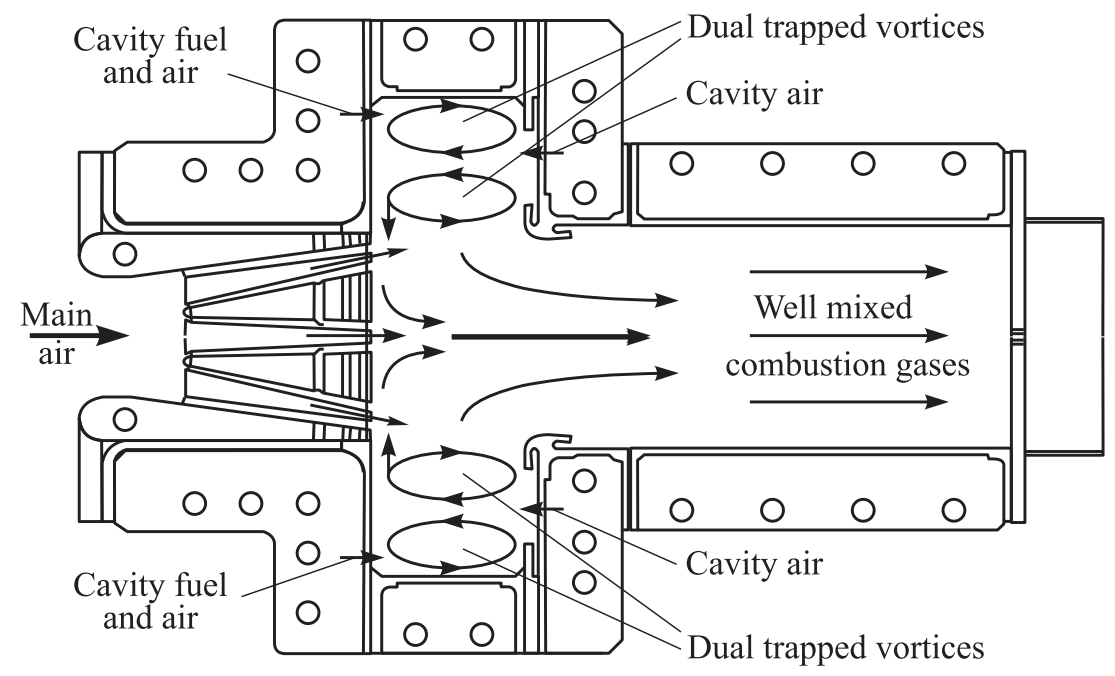

(a)

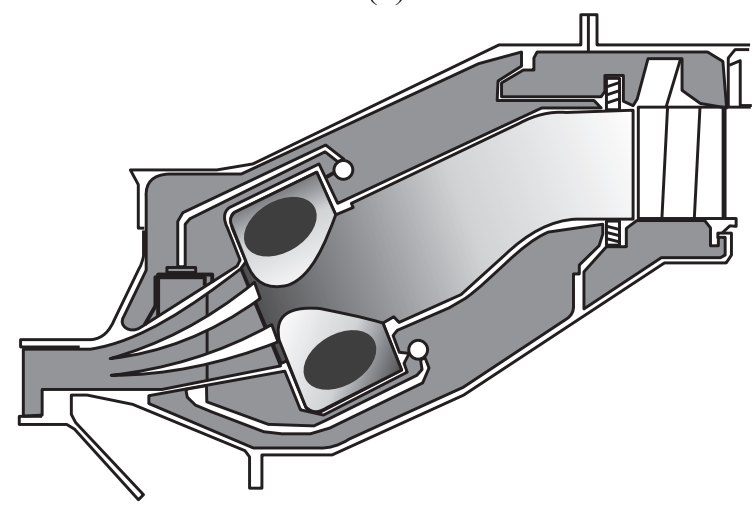

(b)

Figure 14 The TVC: (a) a sketch of the combustor use in GE work [41] and (b) a notion suggestive of a possible axisymmetric installation (AFRL release)

gions near surfaces, or in corners and around obstacles may be responsible. Unsteady viscous effects, causing fluctuations of composition and mixture ratio, locally can be significant. Small changes become relatively more important as the average equivalence ratio is reduced. Fluctuations of flame speed due to the fluctuations of composition may combine with other compositional effects to encourage flame 'blowout.' Whatever may be the details, the main result is a general weakening of the processes responsible for anchoring the flame. Note 
the general characteristic that purely fluid mechanical processes are centrally important.

In an RQL combustor, such effects are absent, or at worst much reduced, in the rich region near the head end where injection of the combustible mixture occurs. Further downstream where effects similar to those found in lean combustors may occur, the effects on overall flame stability are considerably reduced, because much of the flame region is stabilized already by the processes in the rich region. Because of the general nature of the combustion processes in the chamber taken as a whole, the reaction processes are relatively more smeared out in the RQL combustor. The fact that the RQL combustor is in some general sense more of a nonequilibrium system than is a lean system, is a fundamental reason for the striking differences in stability.

At this time, then, the two types of combustor are quite well-defined. Their respective limits of performance are not so well established. On balance, however, it appears that combustors operating with premixed lean reactants are better understood than RQL or related devices depending in fundamental ways on nonequilibrium processes. Probably, the 'return-on-investment' in research is potentially much greater for the second class of devices.

\section{SOME EXPERIMENTAL RESULTS}

Determining the lower limits on emissions for a given combustor design is a very tedious and imprecise process, particularly, if it is carried out empirically with tests of the full-scale device. A similar situation prevails for establishing the stability limits. It is a fundamental obstacle to formulating design guidelines and procedures that surprisingly little attention has been paid to certain basic problems that must be better understood to achieve further progress. Considered briefly in this section is one modest example related particularly to a possible mechanism for combustion instabilities in lean combustors.

A complete formulation of the problem of instabilities shows explicitly that the frequency response of combustion processes is a fundamental factor. In the case of solid propellant rockets, approximate analyses in the 1950s showed that the admittance function for a burning surface has behavior dominated under practical conditions by unsteady heat conduction in the solid phase. The frequency response of the surface consequently is amplified in a frequency range which also captures many acoustic modes for practical rocket combustors, a few hundred to several thousand hertz.

Much effort, and money, has been spent as workers in many countries have attempted to gain necessary information about the responses ('admittance functions') for actual propellants. The field is still active as practical problems continue to arise, and fundamental problems remain. There seemed reason to expect 
that similar processes would likely be active in gas-turbine combustors. The research described in this section was initiated to investigate the question.

An unexpressed, but surely implied, hope (expectation?) accompanying the introduction of feedback control as a means of combating instabilities in gasturbine combustors, was that the dreadful obstacles encountered with problems of stability similar to that in solid rockets would be avoided. The magic of feedback would do the job. That kind of sanguine view may have had much to do with the character of research funded in the field for two decades. But it seems that the unsatisfactory state of success and lack of recent progress may suggest that there is no substitute for understanding the problems that are basic to the field.

In the middle to late 1990s, laser-based methods became available to investigate the time and spatial characteristics of distributed combustion processes. Building on early works [42, 43], a program was initiated at Caltech to measure the frequency response of flames at atmospheric pressure. There were two principal methods available at that time: $(i)$ passively observed chemiluminescence and ( $i i)$ planar laser induced fluorescence (PLIF). The great advantage of PLIF, which is far more difficult to use and requires relatively expensive special equipment and data processing, is that it offers unmatched opportunities for spatial and temporal resolution. For extended explanatory coverage, see two Ph.D. dissertations $[43,44]$ as well as several published papers.

Sketches of the apparatus used for the two different sorts of experiments are given in Fig. 15. In both cases, flames are immersed in steady acoustic fields. The geometries used, and frequency ranges covered, are such that the flames are exposed to uniform oscillating pressure fields. In support of the main conclusion given below, some results obtained with observations of chemiluminescence from a flat methane flame are briefly discussed.

Chemiluminescence is measured using a photomultiplier tube coupled to a Nikon F/1.2 lens which views the flame through one of the side windows of the test section. An optical band-pass filter is used to reject all incoming light except that associated with $\mathrm{CH}$ and $\mathrm{CO}_{2}$ chemiluminescence. The photomultiplier tube (PMT) signal is fed to a transimpedance preamplifier which provides gain and also separates the alternating current (AC) and direct current (DC) signal components. The DC component, which represents the average heat flux to the flame, $\bar{q}$, is fed directly back to the data acquisition (DAQ) computer and is measured. The AC component, which represents $q^{\prime}$, is fed to an EG\&G dualphase lock-in analyzer. This unit uses the oscillator signal from the AFC-100 as its reference input and measures the magnitude and phase of the $q^{\prime}$ signal. The lock-in analyzer has substantial sensitivity and noise rejection capability and, in this experimental configuration, is capable of resolving $q^{\prime} / \bar{q}$ ratios down to $10^{-7}$.

Once all the data is returned to the DAQ computer, it is used to calculate one point of the combustion response function: 


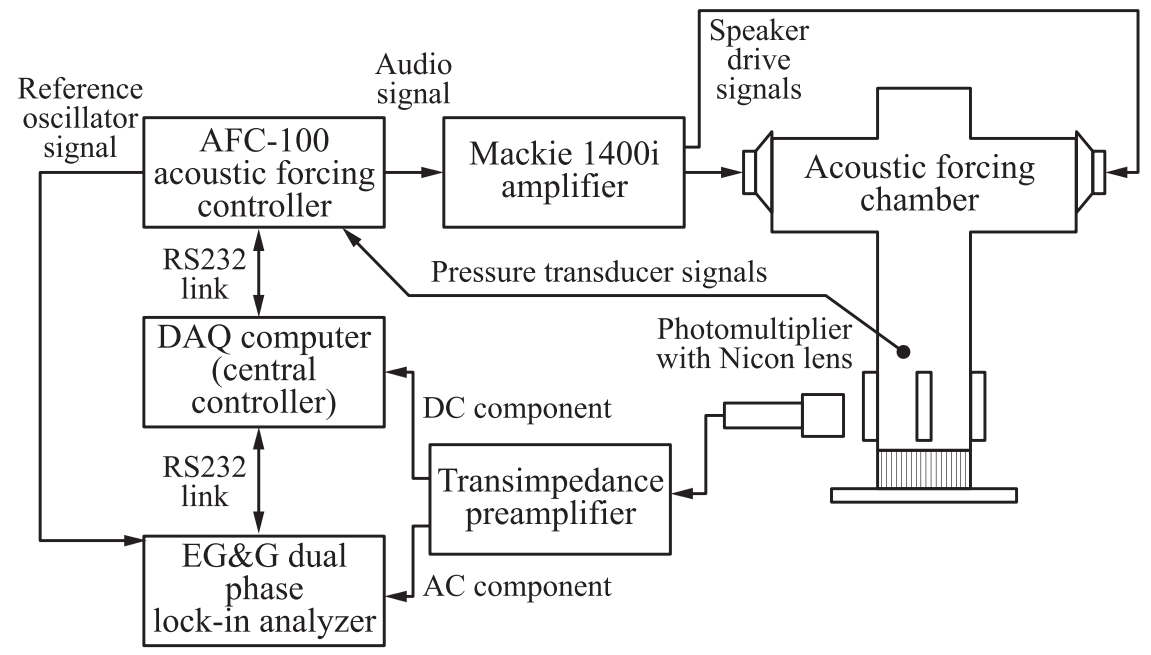

(a)

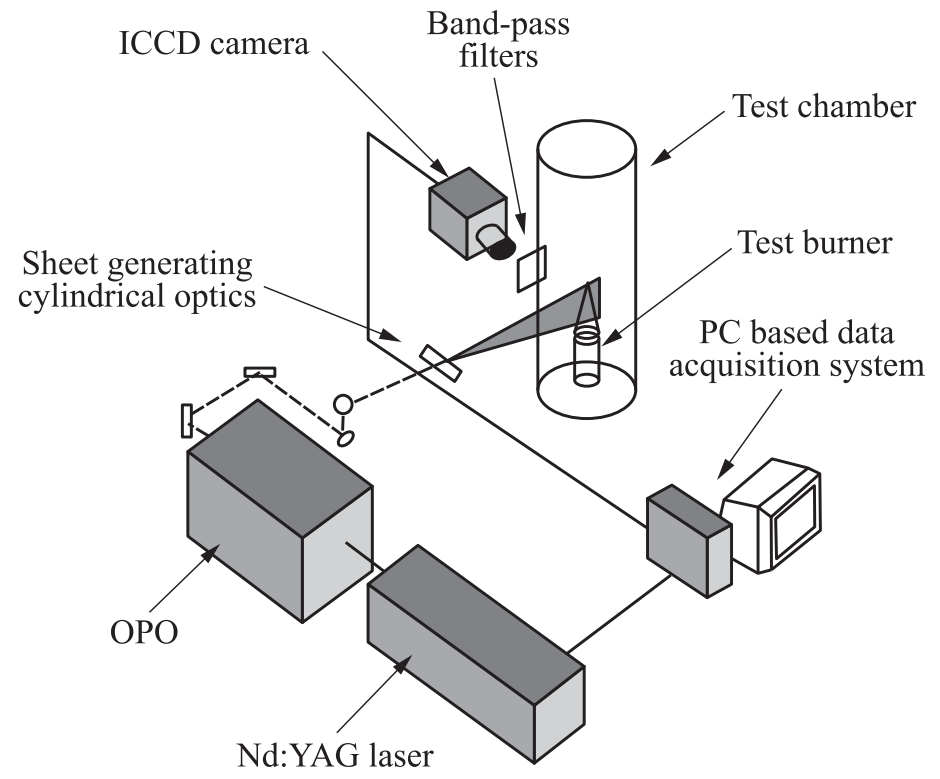

(b)

Figure 15 Experimental configurations used for measurements of the frequency response of combustion regions: (a) chemiluminescence and (b) PLIF 


$$
H(s)=\frac{q^{\prime}(s) \bar{p}(s)}{\bar{q}(s) p^{\prime}(s)} ; \quad s=j \omega .
$$

This combustion response function from 20 to $1800 \mathrm{~Hz}$ is synthesized by continuously repeating this operation while the drive frequency is swept. This entire operation is fully automated.

The burner currently being tested is a bluff-body stabilized, flat-flame burner. In this device, premixed methane and air pass through a converging nozzle, leaving the nozzle exit as a free jet. This jet impinges upon a water cooled stagnation plane, oriented normal to the direction of flow. The diameter of the jet at the nozzle exit is $14 \mathrm{~mm}$ and the nozzle shape is designed to produce a top-hat velocity profile at this location.

As the jet approaches the stagnation plane, the axial velocity decreases while the radial velocity increases. The flat flame is stabilized in this gap where the flame speed matches the local velocity normal to the flame surface. The burner has been operated from equivalence ratios of 0.625 to 1.0 with typical nozzle exit velocities ranging from 30 to $200 \mathrm{~cm} / \mathrm{s}$.

Experiments were performed on the burner with the bluff body positioned $21 \mathrm{~mm}$ above the nozzle exit. The burner was operated on premixed methane (99.995\% pure) and dry air. The sound pressure level of the acoustic field at the flame location was approximately $110.7 \mathrm{~dB}$. In the data presented here, four conditions were run with equivalence ratios of $0.70,0.75,0.80$, and 0.85 . For these four conditions, the total mass flow rate was adjusted to hold the flame strain rate roughly constant. In each case, the bluff-body was allowed to come to thermal equilibrium prior to starting the experiment. Results of the experiments are shown in Fig. 16. The combustion response function is the same as that defined above.

As can be seen, the peaks in the magnitude plots all occur between 20 and $60 \mathrm{~Hz}$. The peak in the response increases and shifts to the right (toward higher frequency) as the equivalence ratio is increased. After their peaks, each curve rolls off to a combustion response magnitude around 10. At this point, the curves exhibit notch behavior and then level off at a combustion response level of approximately 8. Similar to the response peaks, the frequencies at which the notches occur increase with equivalence ratio.

The curves essentially coalesce and then make transitions through the broad peaks between 200 and $500 \mathrm{~Hz}$. This behavior is due to the Helmholtz resonance associated with the burner cavity. The dashed curve in the bottom of the magnitude plot shows the fluctuating pressure measured inside the burner cavity at the base of the nozzle.

The phase plots show similar behavior for all the curves at low frequencies,. although it is unclear which zero phase point (i.e., $-360^{\circ}, 0^{\circ}$, or $+360^{\circ}$ ) each curve is approaching as the frequency tends to zero. For low frequencies, each curve appears to be rolling off like a time delay. However, at the point where 

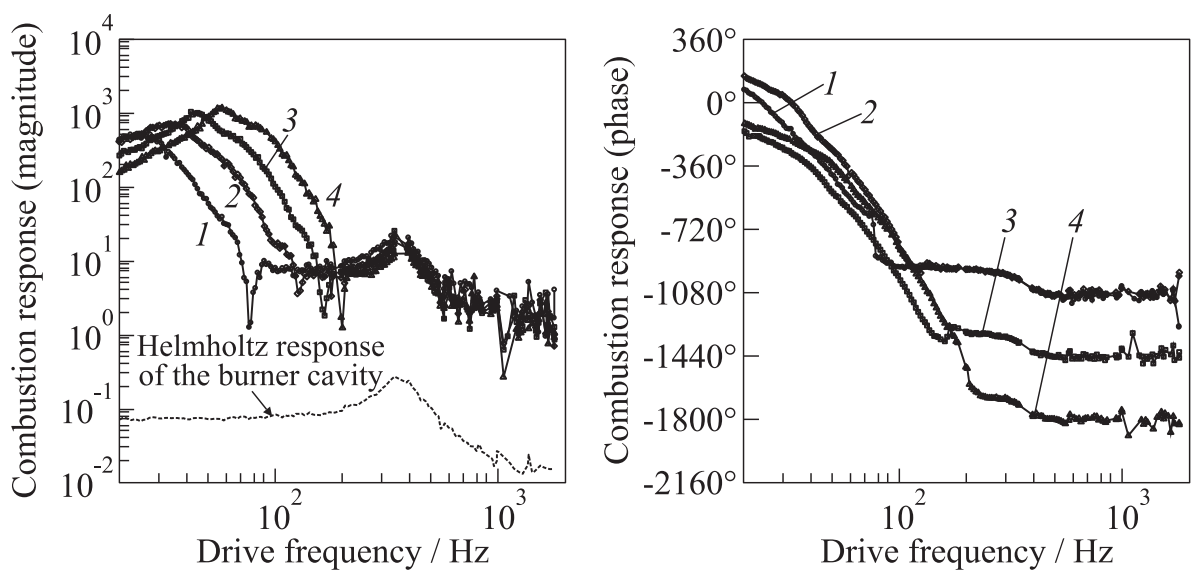

Figure 16 Combustion response of burner at constant strain rate and various equivalence ratios: $1-0.70 ; 2-0.75 ; 3-0.80$; and $4-0.85$

their corresponding notch occurs in the magnitude plot, each phase curve makes a jump. It appears that these jumps occur in order to put the curve on a path to have zero phase $\left(q^{\prime}\right.$ in phase with $\left.p^{\prime}\right)$ at high frequency. As can be seen, these jumps do not have the same magnitude, or even the same direction. They also do not necessarily end up on the same phase wrap with each other. Interestingly, it appears that the size of the jump in the phase plot and the depth of the notch in the magnitude plot may be related. Larger jumps in the phase seem to be associated with deeper notches in the magnitude.

The results recorded in Fig. 16 are broadly consistent with those reported previously, including data taken with PLIF for partially unmixed, nonflat flames. And they are indeed surprising, for apparently they mean that the frequency response of premixed methane flames is strongly dependent on frequency only for frequencies less than a few hundred hertz. This conclusion suggests further that for combustion instabilities, the dynamical behavior of combustion processes can be approximated by a relatively simple response function, approximately constant (but having a fairly large value), independent of frequency. Much remains to be done to ensure that for the results shown here, the responses of the chamber and supply apparatus have been properly taken into account.

If these conclusions and interpretations of combustion dynamics are correct, then the result has important implications for continuing work on oscillations in gas turbines. It appears that efforts should be concentrated on understanding the basic properties of the steady and unsteady flow fields. A similar situation has arisen many times for instabilities in solid rockets, particularly strategic motors and launch boost systems. In those cases, special forms of the local steady field 
have been found to have dominant influences on the unsteady fields. Processes transferring energy from the steady three-dimensional velocity fields to acoustic fields often cause troublesome instabilities. Several important examples have been discussed by Culick [5]. The most recent work has been done in connection with the Ariane 5 booster motors; the case for gas turbine combustors is most clearly made by the Siemens experience summarized above.

The obvious importance of unsteady combustion processes and their coupling to acoustical motion must not be forgotten! They are particularly evident in the many studies of instabilities under lean conditions, notably those directed to defining LBO limits. Probably, GE has had the most extensive continuous research program (see [38] for a good introduction) of any organization. However, as seems almost always to be the case, and is appropriate in an industrial setting, emphasis has been placed on trying to treat today's problems today.

\section{CONCLUDING REMARKS}

When Bollay proposed active control of combustion dynamics in 1951, he had in mind an application quite different from those which have driven research in the field during the past twenty years. His motivation, oscillations in liquid rockets, in fact became an increasingly severe problem. It has been "solved" for practical purposes by a combination of results and experience gained from large numbers of tests; and reasoning guided, sometimes imperfectly, by incomplete theory.

Combustion instabilities in thrust augmentors have been a continuing problem. They have typically restricted portions of the operating envelope. Likely due to a suggestion by Prof. Ffowes-Williams, Rolls Royce, Ltd. funded a research program at Cambridge in augmentor instabilities that included the first successful experiments with active control. In the initial tests, loudspeakers were used as actuators, but in the early 1990s, the Cambridge group first demonstrated, in a simple channel, control of oscillations by modulation of the fuel supply. It was a single-input-single-output system. A modest amount of analysis accompanied the demonstrations, analysis which aided ex post facto interpretations, but was in no sense predictive.

That Cambridge work, followed shortly by a program also involving École Centrale, Paris, collaborating with groups in Munich and Lyons, in many ways defined the broad outlines of many works in the early to mid-1990s. Research in the field was pursued vigorously, and several dissertations prepared at Technische Universität, München produced, significantly, a new magnetostrictive actuator. That was an important item incorporated in a MIMO system installed in 270megawatt Siemens power generators to combat a combustion instability. It is the only case of full-scale operating systems with active control of combustors. With installations in fourteen machines, approximately 140,000 hours of operation 
were accumulated. Continued studies clarified the mechanism of the instability; relatively simple mechanical modifications ('passive control') then allowed the active control system to be discarded.

Because of inevitable problems of instabilities accompanying development of LP and LPP combustors for gas turbines, research has continued to the present time, although presently with subdued general enthusiasm. Refinements of familiar sorts of equipment have produced much interesting data using for the most part well-established methods. Most of the observed behavior is poorly understood. In fact, virtually all the experimental results have not been satisfactorily explained. There is not one case involving active control of a combustion instability for which the unstable motion has been predicted and the subsequent effect of control predicted as well. On the one hand, it is easily understood why such a situation exists - the problems are indeed difficult. But it is not easily understood why so little effort seems to have been exerted in trying to correct such an obvious deficiency. As experience in the field of solid rocketry has shown, much can be learned, especially from approximate analyses of instabilities. Such theoretical results often suggest informative small-scale experiments.

Unfortunately, it seems that much of the research done in this field, especially in the U.S., has been very applied. That is, experimental work has often been directed to solving problems which have been identified by manufacturers as begging solution in the very near future. Government funded programs have unfortunately often responsively been formulated to satisfy the same needs. That characteristic has been commonly shared irrespective of national borders. As a result, it is believed, when practical problems are found, there are few general principles to fall back upon, and a sad absence of well-established guidelines. Advances in theoretical and experimental methods have not received the continuing support they merit.

The great difficulty of discovering the true mechanisms of combustion instabilities is perhaps the greatest obstacle to eliminating them. Probably, the situation is fairly well-in-hand for LP and LPP systems; operational limits can be set by extensive testing. The lengthy development program documented for thirty years by GE gives evidence of considerable success and represents essentially the "state-of-the-art." There are some people who believe that the limits of those types of combustors may have been reached. That is, emissions ( $\mathrm{CO}$ and oxides of nitrogen) cannot be reduced further. That belief is well-founded, being based on test and operational results.

Whether the comparable state has been reached for RQL, or the unproven trapped vortex idea, cannot be stated. (There is no Second Law of pollutant emissions.) Simply not enough is known about the systems to state limits with confidence. That reasoning is partly behind justification of the experimental work touched upon in the last section. It is fairly clear that nonintrusive methods offer the only promising basis for obtaining good spatial resolution of timedependent behavior for combusting systems. 
Several laser-based techniques are available, but it appears that some form of PLIF alone presently offers the possibilities sought. Chemiluminescence has proven very useful in several applications, but its simplicity is paid for with severe reductions in spatial and temporal resolution, as well as with a loss of information about the details of local chemistry. In some configurations, only global characteristics are available.

There are many other promising possibilities for research programs, not covered here. Theoretical, numerical (CFD plus combustion), and experimental methods all are far from the ends of their development. Moreover, the conceivable stakes are very high indeed. What is required, as usual, is resolve and intelligent planning.

As always is the case, investments in research, only a portion leading to practical realizations, will be repaid handsomely; confident and informed leadership is essential.

\section{ACKNOWLEDGMENTS}

Preparation of this paper and the equipment required for the experiments reported in Section 5 were financially supported by the authors. The early Caltech work was supported by the Air Force Office of Scientific Research, 19982003, the period when the first versions of the equipment shown in Fig. 15 were constructed. The authors are indebted to several people, particularly Dr. G. Sturgess, for useful discussion of the material covered in the last part of Section 4.

\section{REFERENCES}

1. Bollay, W. 1951. Aerodynamic stability and automatic control. J. Aero Sci. 18(9):569-640.

2. Tsien, H.S. 1952. Servo-stabilization of combustion in rocket motors. ARS J. 22:256-63.

3. Hermann, J., A. Orthmann, and S. Hoffman. 1999. Application of active instability control to a heavy duty gas turbine. XIV ISABE. Paper A99-34186.

4. Berenbrink, P., and S. Hoffmann. 2000. Suppression of dynamic combustion instabilities by passive and active means. ASME Turbo Expo 2000. Paper 2000-GT-0079.

5. Culick, F.E. C. 2006. Unsteady motions in combustion chambers for propulsion systems. AGARDograph RTO-AG-AVT-039.

6. Dines, P. J. 1983. Active control of flame noise. Ph.D. Thesis. University of Cambridge. 
7. Heckl, M. A. 1986. Active control of the noise from a Rijke tube. IUTAM Symposium on Aero and Hydro-Acoustics Proceedings. Springer-Verlag. 211-16.

8. Heckl, M. A. 1988. Active control of the noise from a Rijke tube. J. Sound Vib. 124(1):117-33.

9. Ffowcs-Williams, J. E., P. J. Dines, and M. A. Heckl. 1985. Combustion system for a gas turbine. U.S. Patent 4,557,106.

10. Langhorne, P. J. 1988. Reheat buzz: An acoustically coupled combustion instability. Part 1. Experiment. J. Fluid Mech. 193:417-43.

11. Bloxsidge, G. J., A. P. Dowling, N. Hooper, and P. J. Langhorne. 1987. Active control of an acoustically driven combustion instability. J. Theor. Appl. Mech. Supplement to Vol. 6. 161-75.

12. Moran, A. J., D. Steele, and A. P. Dowling. 2000. Active control of combustion and its applications. RTO AVT Symposium on Active Control Technology for Enhanced Performance Operational Capabilities of Military Aircraft, Land Vehicles and Sea Vehicles. Braunchweig, Germany.

13. Lang, W., T. Poinsot, and S. M. Candel. 1987. Active control of combustion instability. Combust. Flame 70(3):281-89.

14. Poinsot, T., D. Veynante, F. Bourienne, S. M. Candel, E. Esposito, and J. Surget. 1988. Initiation and suppression of combustion instabilities by active control. 22nd Symposium (International) on Combustion. The Combustion Institute. 1363-70.

15. Poinsot, T., F. Bourienne, S. M. Candel, E. Esposito, and W. Lang. 1989. Suppression of combustion instabilities by active control. J. Propul. Power 5(1):14-20.

16. Fung, Y. T., V. Yang, and A. Sinha. 1991. Active control of combustion instabilities with distributed actuators. Combust. Sci. Technol. 78(6):217-45.

17. Fung, Y. T., and V. Yang. 1992. Active control of nonlinear pressure oscillations in combustion chambers. J. Propul. Power 8(4-6):1282-89.

18. Gulati, A., and E.C. Bigelow. 1990. Control of combustion instabilities. U.K. Patent Application, GB 2,239,961 A, Application No. 9027565.2.

19. Hantschk, C., J. Hermann, and D. Vortmeyer. 1996. Active instability control with direct-drive servo valves in liquid-fueled combustion systems. 26th Symposium (International) on Combustion. The Combustion Institute. 2835-41.

20. Hermann, J., S. Gleis, and D. Vortmeyer. 1996. Active instability control (AIC) of spray combustors by modulation of liquid flow rate. Combust. Sci. Technol. 118(1):1-25.

21. Hermann, J., A. Orthmann, S. Hoffmann, and P. Berenbrink. 2000. Combination of active instability control and passive measures to prevent combustion instabilities in a $260 \mathrm{MW}$ heavy duty gas turbine. RTO AVO Symposium on Active Control Technology for Enhanced Performance Operational Capabilities of Military Aircraft, Land Vehicles and Sea Vehicles. Braunschweig, Germany.

22. Schadow, K. C., V. Yang, F.E. C. Culick, T. J. Rosfjord, G. Sturgess, and B. T. Zinn. 1997. Active combustion control for propulsion systems. AGARD Report 820.

23. Zel'dovich, Ya. B., G. I. Barenblatt, V.B. Librovich, and G. M. Mikhviladze. 1985. The mathematical theory of combustion and explosions. Translated from the Russian by D. H. McNeill. N.Y.: Consultants Bureau (Plenum Press). 
24. Lieuwen, T., and V. Yang. 2005. Combustion instabilities in gas turbine engines. AIAA progress in astronautics and aeronautics ser.

25. Neumeier, Y., and B. T. Zinn. 1996. Experimental demonstration of active control of combustion instabilities using real time modes observation and secondary fuel injection. 26th Symposium (International) on Combustion. The Combustion Institute 2:2811-18.

26. Zinn, B. T. 2005. Smart combustors - just around the corner. ASME Turbo Expo 2005. Paper GT2005-69138.

27. Neumeier, Y., and B. T. Zinn. 1998. Methods, apparatus and systems for real time identification and control of modes of oscillation. U.S. Patent No. 5,719,791.

28. Johnson, C. E. 2006. Adaption control of combustion instabilities using real-time modes observation. Ph.D. Dissertation. Mechanical Engineering, Georgia Institute of Technology.

29. Åstrom, K. J., and B. Wittenmark. 1995. Adaptive control. Reading, MA: AddisonWesley Publishing Co.

30. Billoud, G., M. A. Galland, C. Huynh Huu, and S. E. Cancel. 1992. Adaptive active control of combustion instabilities. Combust. Sci. Technol. 81(4):257-83.

31. Evesque, S. 2000. Adaptive control of combustion instabilities. Ph.D. Dissertation. University of Cambridge.

32. Evesque, S., and A. P. Dowling. 2001. LMS algorithms for adaptive control of combustion oscillations. Combust. Sci. Technol. 164(1):65-93.

33. Evesque, S., A.P. Dowling, and A. Annaswamy. 2003. Self-tuning regulators for combustion oscillations. Proc. R. Soc. London, Ser. A 459(2035):1709-49.

34. Lieuwen, T., H. Torres, C. Johnson, and B. T. Zinn. 2001. A mechanism of combustion instability in lean premixed gas turbine combustors. J. Eng. Gas Turbine Power 123:182-89.

35. Roberts, R., A. Fiorentino, and W. Greene. 1977. Experimental clean combustion program. Part III: Final report. NASA CR-135253.

36. Gleason, L. C., and D. W. Bahr. 1979. Experimental clean combustion program. Part III: Final Report. NASA CR-135384.

37. Sabnis, J. 2005. Emissions and noise: The next frontier for airfcraf engine technologies. AIAA/AAAF Aircraft Noise and Emission Reduction Symposium. Monterey, CA.

38. Mongia, H., T. J. Held, G. C. Hsia, and R.P. Panaandalai. 2005. Incorporation of combustion instability issues into design process: GE aeroderivative and aero engines experience. In: [24]. Ch. 3.

39. Hoke, J. B., I. Segalman, K. S. Suskind, and R. D. C. Smith. 2001. Low NOX combustor for gas turbine engine. U.S. Patent No. 6,240,731 B1.

40. Hura, H.S., and H. C. Mongia. 1998. Prediction of NO emission from a lean dome gas turbine combustor. AIAA Paper No. 98-3375.

41. Haynes, J., J. Janssen, C. Russell, and M. Hoffman. 2006. Advanced combustion systems for next generation gas turbines. GE Global Research. Report DE-FC26OINT41020. 
42. Pun, W., S. Palm, and F.E. C. Culick. 2000. PLIF measurements of combustion dynamics in a burner under forced oscillatory conditions. AIAA Paper No. 20003123.

43. Pun, W. 2001. Measurement of thermo-acoustic coupling. Ph.D. Thesis. California Institute of Technology.

44. Kang, D. M. 2006. Measurements of combustion dynamics with laser-based diagnostic techniques. Ph.D. Thesis. California Institute of Technology. 